Supporting Information for

\title{
Electrical Conductivity-Relay between Organic Charge-Transfer and Radical Salts toward Conductive Additive-Free Rechargeable Battery
}

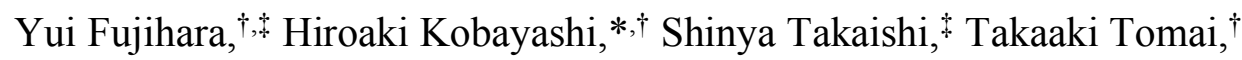

Masahiro Yamashita, ${ }^{\star}, \|$ and Itaru Honma ${ }^{\dagger}$

†Institute of Multidisciplinary Research for Advanced Materials, Tohoku University, 2-1-1

Katahira, Aoba-ku, Sendai, Miyagi, 980-8577, Japan.

Department of Chemistry, Graduate School of Science, Tohoku University, 6-3 Aramaki-AzaAoba, Sendai 980-8578, Japan.

${ }^{\S}$ WPI Research Center, Advanced Institute for Materials Research, Tohoku University, 2-1-1 Katahira, Aoba-ku, Sendai 980-8577, Japan.

"School of Materials Science and Engineering, Nankai University, Tianjin 300350, China.

*Corresponding author

Email: h.kobayashi@tohoku.ac.jp

ORCID: 0000-0001-6705-9515 


\section{Section S1. Supplemental figures (Figure S1 and S2):}

(a)

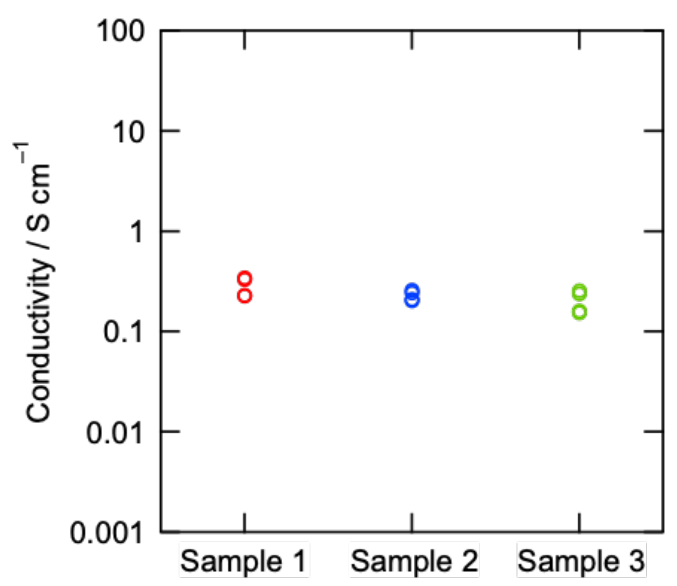

(b)

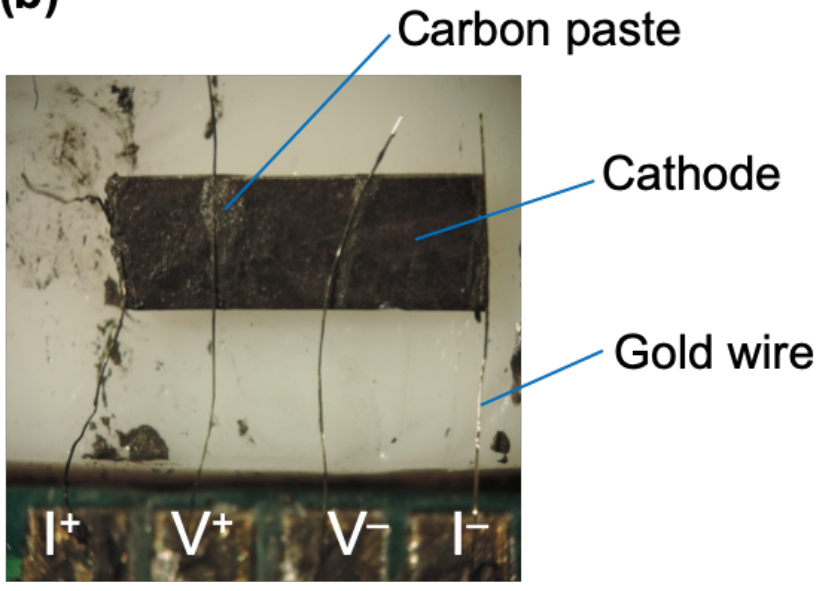

Figure S1. (a) Electrical conductivity of TTF-TCNQ MCC cathode at $300 \mathrm{~K}$ with four probe method. Each sample was measured four times and each color shows each sample. (b) A picture of four probe method for TTF-TCNQ MCC cathode.

(a)

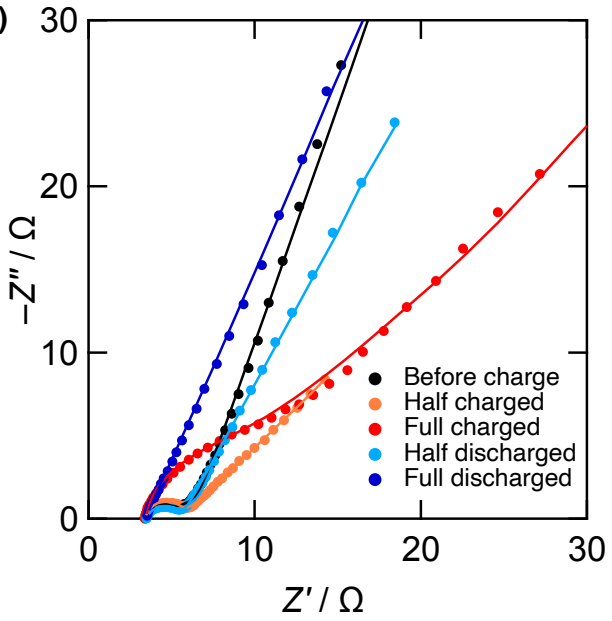

(b)

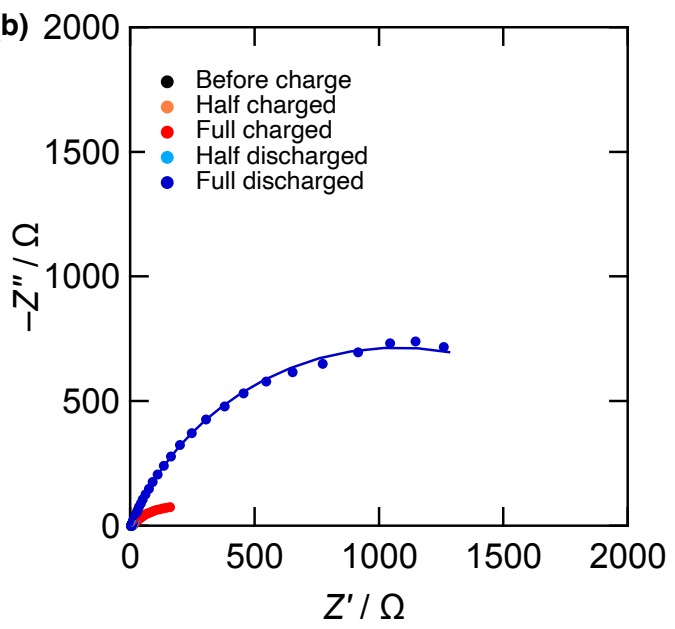

Figure S2. Overall EIS spectra of Figure 5. 


\section{Section S2. Assignment of electrochemical reactions for process I $\sim$ :}

To understand the electrochemical reactions during charge-discharge, cyclic voltammetry (CV) of the MCC cathode was performed as shown in Figure S3a, S3b. In the CV curve displayed in Figure S3a, several peaks were overlapped together, so step-by-step CV measurements with regulating oxidation potentials were carried out to confirm redox pairs as displayed in Figure S3b. According to the $\mathrm{CV}$ curves, when oxidation potential was restricted to $0.34 \mathrm{~V}$ (red line in Figure S3b), only one reduction peak at about $-0.2 \mathrm{~V}$ appeared as the reverse reaction. In the case with oxidation potential was restricted to $0.43 \mathrm{~V}$ (purple line), another reduction peak at about $-0.4 \mathrm{~V}$ appeared in addition to the previous one as the reverse reaction of the oxidation process at around $0.43 \mathrm{~V}$. As the same way was applied to the oxidation potential limit of $0.53 \mathrm{~V}$ (green line) and $0.6 \mathrm{~V}$ (orange line), all reduction peaks were assigned as the reverse reaction of each oxidation process. We call these four reversible reaction pairs as Process I $\sim$ IV as seen in Figure S3a.These redox pairs were attributed to the plateaus in the constant current (CC) voltage curves (Figure 9 in the main body) considering the different overpotentials between CV curves and CC voltage curves. The plateaus observed at highest voltage in both the charge and discharge curves did not appear in the CV curves due to the overpotential, and was called as Process V. 
(a)
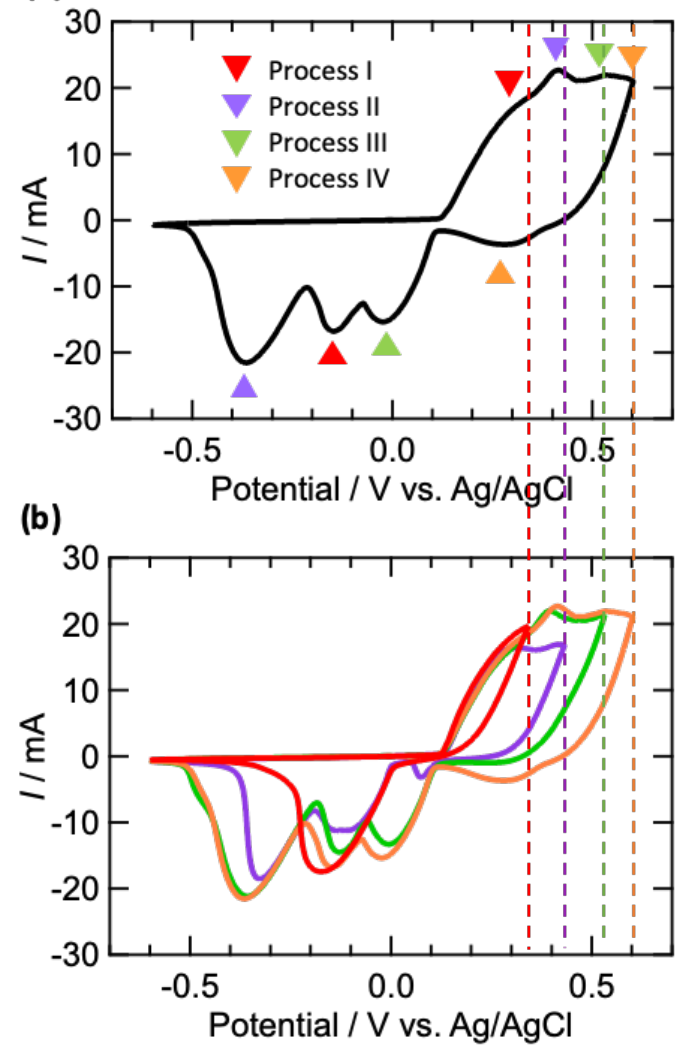

Figure S3. (a) Cyclic voltammetry of MCC cathode. (b) Step-by-step CV measurements with regulating oxidation potentials of $\mathrm{MCC}$ cathode.

Next, each redox reactions of these processes were assigned. First, from the charge-discharge curve, reaction potential of each process was calculated as follows: potential values at the middle of plateaus were taken, and that potential values of charge and discharge in each process were averaged. Potential of CC voltage curves were employed instead of the potential of CVs because accurate peak top potentials were not able to be decided in CV because four peaks were overlapped together. The reaction potential of each process was shown in the Table S1 below. 
Table S1. Reaction potential of each process.

\begin{tabular}{|c|c|c|c|c|c|}
\hline & Process I & Process II & Process III & Process IV & Process V \\
\hline $\begin{array}{l}\text { Reaction potential } \\
\text { (V vs. } \mathrm{Ag} / \mathrm{AgCl})\end{array}$ & 0.065 & 0.073 & 0.23 & 0.40 & 0.48 \\
\hline
\end{tabular}

Scott et al. reported that TTF exhibits the valence state of only $+0.59,+n(0.7 \leq n \leq 0.8),+1$, and +2 with $\mathrm{Br}^{-1}{ }^{1}$ Moreover, Shaw et al. reported that solid $\mathrm{TTFBr}_{n}$ forms directly when solid TTF is electrochemically oxidized under existence of $\mathrm{Br}^{-}{ }^{-2}$ In the pristine MCC cathode, solid state $\mathrm{TTF}^{0}$ and $\left(\mathrm{TTF}^{0.59+}-\mathrm{TCNQ}^{0.59-}\right)^{0} \mathrm{CT}$ exist, hence $\mathrm{TTF}^{0}$ should be oxidized to $+n$ to form $(\mathrm{TTF}) \mathrm{Br}_{n}$ during the early charge process. The (TTF) $\mathrm{Br}_{n}$ formation reaction is expressed as equation 1 and its redox potential $\left(E_{1 / 2}\right)$ is expressed as the following Nernst equation 2 . Since $E_{1 / 2}$ with $0.1 \mathrm{M} \mathrm{NaBr}$ electrolyte $\left(E_{0.1 \mathrm{M}}\right)$ is $0.09 \sim 0.1 \mathrm{~V}$ vs. $\mathrm{Ag} / \mathrm{AgCl}$ reference, $E_{1 / 2}$ with $1 \mathrm{M} \mathrm{NaBr}$ electrolyte $\left(E_{1 \mathrm{M}}\right)$ should be around $0.03 \sim 0.04 \mathrm{~V}$ according to equation $3 .^{2}$

$$
\begin{array}{r}
\mathrm{TTF}+n \mathrm{Br}^{-} \rightleftarrows(\mathrm{TTF}) \mathrm{Br}_{n}+n \mathrm{e}^{-} \\
E=E^{\circ}+\frac{0.0592}{n} \log \frac{1}{[B r-]^{n}} \\
E_{1 M}=E_{0.1 M}-0.0592 \approx E_{0.1 M}-0.06(V)
\end{array}
$$

Compared with the value at Table S1, the closest Process I should correspond to this reaction. Although the reaction behavior of $\mathrm{TTF}^{0.59+}$ existing together with $\mathrm{TTF}^{0}$ at the $\mathrm{MCC}$ cathode is still unclear, it perhaps reacts in the similar way because the first plateau of 2nd charge of CT complex cathode (Figure S3a) showed similar voltage to that of the MCC cathode. It also supports this idea 
that the shape of whole CC voltage curves of CT complex cathode at 2 nd cycle was similar to that of the MCC cathode.

On the other hand, Bond et al. reported the electrochemical behavior of solid TCNQ under existence of $\mathrm{Na}^{+}{ }^{3}$ They reported redox reaction of $\mathrm{TCNQ}^{0 /-}$ occurred at $134 \mathrm{mV}$ of $E_{1 / 2}$ at $0.1 \mathrm{M}$ of $\mathrm{NaCl}$ and electrochemical characteristic were independent of identity. In the same way as equation $1 \sim 3$, the reaction is written as equation 4 , and $E_{1 / 2}$ with $1 \mathrm{M} \mathrm{Na}^{+}$electrolyte $\left(E_{1 \mathrm{M}}\right)$ is expressed as equation 5 since TCNQ and NaTCNQ are also solid. $E_{1 / 2}$ value at $1 \mathrm{M}$ of $\mathrm{Na}^{+}\left(E_{1 \mathrm{M}}\right)$ should be around $0.2 \mathrm{~V}$ (equation 5). Compared with Table S1, this should correspond to Process III.

$$
\begin{array}{r}
\text { TCNQ }+\mathrm{Na}^{+}+\mathrm{e}^{-} \rightleftarrows \mathrm{NaTCNQ} \\
E_{1 M}=E_{0.1 M}+0.0592 \approx E_{0.1 M}+0.06(V)
\end{array}
$$

From the same reference, the reaction of $\mathrm{TCNQ}^{-/ 2-}$ seemed to occur below $-0.4 \mathrm{~V}$, which is much lower than any reaction potential and seemed not to occur in this cathode.

As for Process II, IV, V, Process II had the largest polarization and the order of Process I and II in discharging was opposite to charging. So, Process II should not be further oxidation of (TTF)Br ${ }_{n}$. Moreover, $\mathrm{TCNQ}^{0}$ generated at the Process III cannot be oxidized further. From these points, Process IV and $\mathrm{V}$ are probably the reactions of $\mathrm{TTF}^{n+} /^{+}$and $\mathrm{TTF}^{+/ 2+}$, respectively. Adeel et al reported the fact that successive reversible oxidation reactions that generate $\mathrm{TTF}^{+}$and $\mathrm{TTF}^{2+}$ occurs after the formation reaction of mixed-valent radical salt when solid TTF is oxidized in different aqueous electrolyte, supporting this assignment of Process IV and V. ${ }^{4}$ The process II is still under investigation. 
The summary of the assignment of Process I $\sim \mathrm{V}$ is shown in the Table S2 below.

Table S2. Reaction of the Process I $\sim$ V.

\begin{tabular}{cc}
\hline Process & Reaction equation \\
\hline Process I & $\mathrm{TTF}^{2} n \mathrm{Br}^{-} \rightleftarrows(\mathrm{TTF}) \mathrm{Br}_{n}+n \mathrm{e}^{-}$ \\
Process II & Investigating \\
Process III & $\mathrm{NaTCNQ} \rightleftarrows \mathrm{TCNQ}+\mathrm{Na}^{+}+\mathrm{e}^{-}$ \\
Process IV & $\mathrm{TTFBr}_{n}+(1-n) \mathrm{Br}^{-} \rightleftarrows(\mathrm{TTF}) \mathrm{Br}+(1-n) \mathrm{e}^{-}$ \\
Process V & $(\mathrm{TTF}) \mathrm{Br}+\mathrm{Br}^{-} \rightleftarrows \mathrm{TTF}^{2+}+2 \mathrm{Br}^{-}+\mathrm{e}^{-}$ \\
\hline
\end{tabular}


Section S3. Supplemental figure (Figure S4):

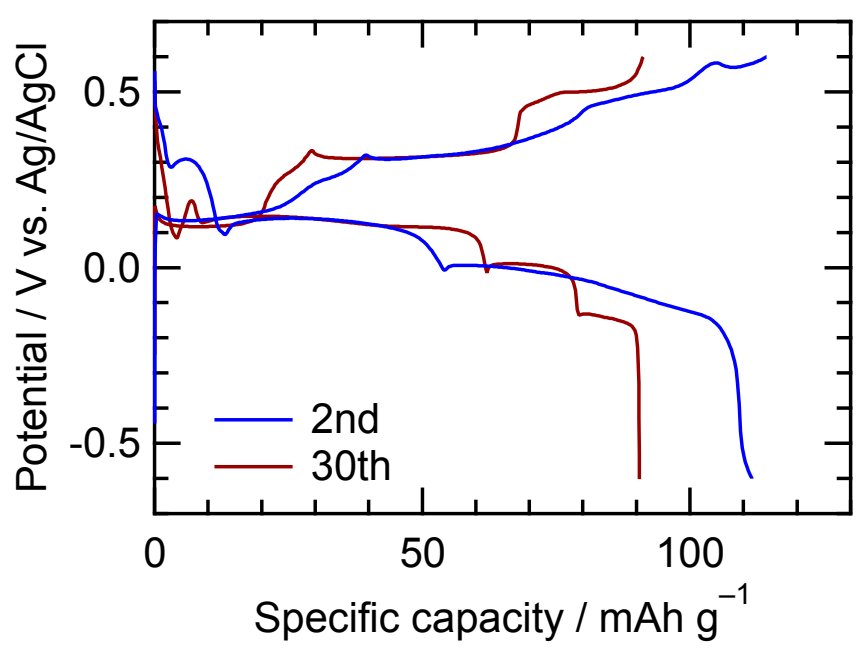

Figure S4. Voltage curves of the MCC cathode in the 2nd and 30th cycle. Plateaus attributed to Process I, II, and III are observed in the 30th cycle, indicating the maintenance of both reaction of TTF and TCNQ. 


\section{Section S4. Comparison of charge-discharge behavior among different electrolytes:}

Charge-discharge cycles of the MCC cathode were tested using different electrolytes such as $1 \mathrm{M}$ $\mathrm{NaCl}$ and $1 \mathrm{M} \mathrm{LiCl}$. In each electrolyte, formed radical salts are shown in Table S3, and they are known to be comparably conductive compared to (TTF) $\mathrm{Br}_{n}$ and NaTCNQ. ${ }^{1,5}$ In the case with the $\mathrm{NaCl}$ electrolyte, although the capacity of initial cycle was similar, the discharge capacity clearly decreased from $100 \mathrm{mAh} \mathrm{g}^{-1}$ (1st) to $50 \mathrm{mAh} \mathrm{g}^{-1}$ (20th). This poor cyclability can be attributed to the higher solubility of (TTF) $\mathrm{Cl}_{n}$ compared to (TTF) $\mathrm{Br}_{n}{ }^{6}$ Furthermore, in the case with $\mathrm{LiCl}$ electrolyte, it exhibited much lower cyclability than $\mathrm{NaCl}$ electrolyte due to the higher solubility of LiTCNQ than NaTCNQ in addition to the solubility of (TTF) $\mathrm{Cl}_{n \cdot}{ }^{6-8}$ This emphasize that the MCC cathode in aqueous $\mathrm{NaBr}$ electrolyte worked well thanks to the low solubility of the $\mathrm{TTFBr}_{n}$ and NaTCNQ radical salts. 
Table S3. Formed radical salts and their conductivity in each electrolyte..$^{1,5}$

\begin{tabular}{lllll}
\hline & Salt with $\mathrm{TTF}^{n+}$ & $\begin{array}{l}\text { Electrical } \\
\text { conductivity } \\
\left(\mathrm{S} \mathrm{cm}^{-1}\right)\end{array}$ & Salt with TCNQ & \\
& & $\begin{array}{l}\text { Electrical } \\
\text { conductivity } \\
\left(\mathrm{S} \mathrm{cm}^{-1}\right)\end{array}$ \\
\hline $\mathrm{NaBr}$ & $\mathrm{TTFBr}_{n}(0.7 \leq n \leq 0.8)$ & $100-500$ & NaTCNQ & $1 \times 10^{-5}$ \\
$\mathrm{NaCl}$ & $\mathrm{TTFCl}_{n}(0.7 \leq n \leq 0.8)$ & $100-500$ & NaTCNQ & $1 \times 10^{-5}$ \\
$\mathrm{LiCl}$ & $\mathrm{TTFCl}_{n}(0.7 \leq n \leq 0.8)$ & $100-500$ & LiTCNQ & $5 \times 10^{-5}$ \\
\hline
\end{tabular}
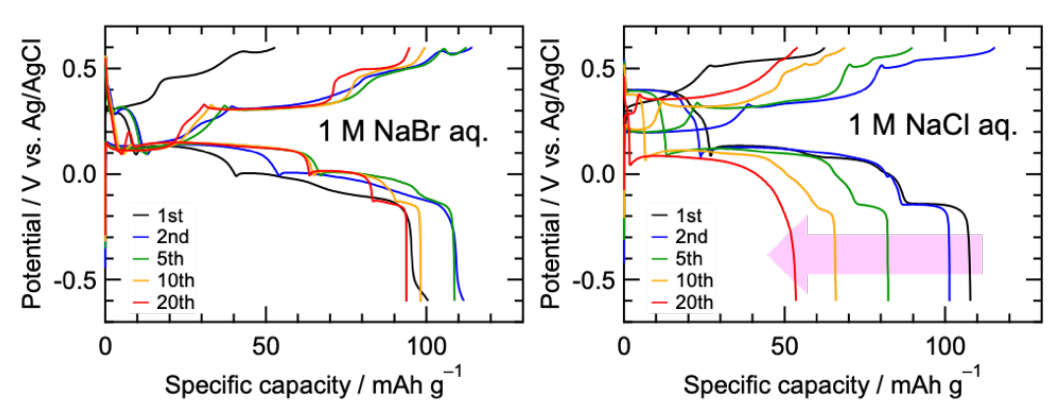

Anion change

(TTF) $X_{n, 1,2}$

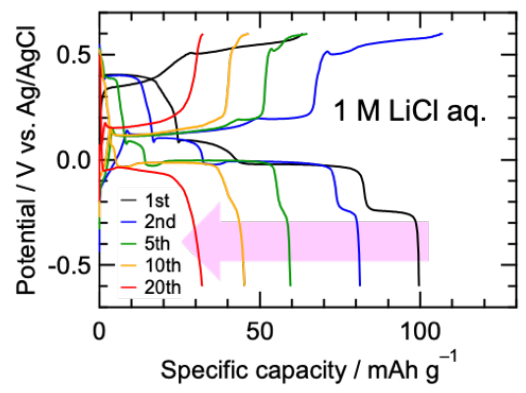

Cation change A(TCNQ)

Figure S5. Voltage curves of the MCC cathode using three electrolytes, aqueous $\mathrm{NaBr}, \mathrm{NaCl}$, and $\mathrm{LiCl}$. 
Section S5. Supplemental figure (Figure S6):

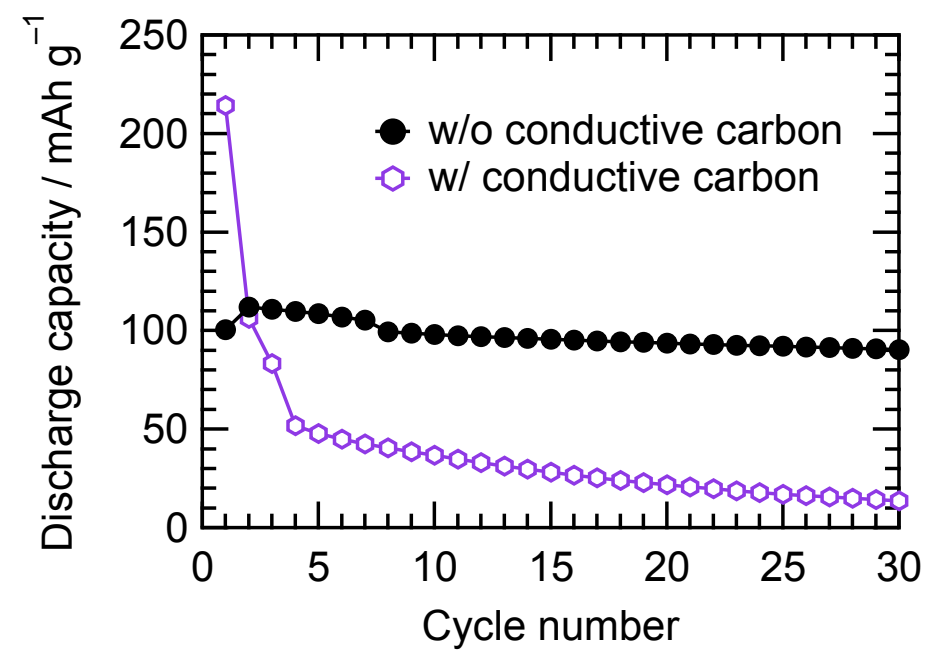

Figure S6. Capacity retention of the MCC cathode with/without conductive carbon with the potential range from $-0.6 \mathrm{~V}$ to $+0.6 \mathrm{~V}$ vs. $\mathrm{Ag} / \mathrm{AgCl}$. 


\section{$\underline{\text { References }}$}

(1) Scott, B.; La Placa, S.; Torrance, J.; Silverman, B.; Welber, B. The crystal chemistry of organic metals. Composition, structure, and stability in the tetrathiafulvalinium-halide systems. J. Am. Chem. Soc. 1977, 99 (20), 6631-6639.

(2) Shaw, S. J.; Marken, F.; Bond, A. M. Detection of new features associated with the oxidation of microcrystalline tetrathiafulvalene attached to gold electrodes by the simultaneous application of electrochemical and quartz crystal microbalance techniques. Electroanalysis 1996, $8(8-9), 732-741$.

(3) Bond, A.; Symons, P. The relationship between the electrochemistry and the crystallography of microcrystals. The case of TCNQ (7, 7, 8, 8-tetracyanoquinodimethane). Analyst 1998, 123 (10), 1891-1904.

(4) Adeel, S. M.; Martin, L. L.; Bond, A. M. Redox-induced solid-solid state transformation of tetrathiafulvalene (TTF) microcrystals into mixed-valence and $\pi$-dimers in the presence of nitrate anions. J. Solid State Electrochem. 2014, 18 (12), 3287-3298.

(5) Siemons, W.; Bierstedt, P.; Kepler, R. Electronic properties of a new class of highly conductive organic solids. J. Chem. Phys. 1963, 39 (12), 3523-3528.

(6) Jaeger, C. D.; Bard, A. J. Electrochemical behavior of tetrathiafulvalenetetracyanoquinodimethane electrodes in aqueous media. J. Am. Chem. Soc. 1979, 101 (7), 1690-1699.

(7) Boyd, R. H.; Phillips, W. D. Solution dimerization of the tetracyanoquinodimethane ion radical. J. Chem. Phys. 1965, 43 (9), 2927-2929.

(8) Bartlett, P. Some studies of electrodes made from single crystals of TTF - TCNQ. $J$. Electroanal. Chem. Interf. Electrochem. 1991, 300 (1-2), 175-189. 